\title{
Performance improvement of heat exchanger using slotted baffle
}

\author{
P. C. Patil ${ }^{*}$ and M. S. Deshmukh \\ Rajarshi Shahu College of Engineering, Tathawade,SP Pune University, Mumbai, India \\ Accepted 15 June 2016, Available online 20 June 2016, Special Issue-5 (June 2016)
}

\begin{abstract}
Heat exchangers are very important heat and mass exchange apparatus in various process industries. Among all types of the heat exchanger shell and tube heat exchangers are commonly and effectively used in industries or applications. Heat exchanger performance can be improved by using various augmentation techniques. Generally in shell and tube heat exchanger segmental baffles are used. The purpose of baffle is to guide the flow and support for tubes. In this study the performance improvement of heat exchanger is done using slotted baffle instead of segmented baffle as segmental baffle have problems like flow induced vibrations etc. Present study aims at developing a heat exchanger model with slotted baffle and comparing the results experimentally with the heat exchanger having segmental baffle.
\end{abstract}

Keywords: Heat Exchanger, Shell and Tube, Slotted baffle, Segmental baffle.

\section{Introduction}

Heat exchangers are device used for transfer of heat between two fluids at different temperature. In the majority of the heat exchangers, a solid wall separates the two fluids so that they are not in direct contact with each other. A shell and tube heat exchanger is a very good example of heat exchanger. As its name implies, this type of heat exchanger consists of a shell (a large pressure vessel) with a bundle of tubes inside the shell. A shell and tube heat exchangers are probably most common type of heat exchangers applicable for wide range of operating temperature and pressure.

Heat exchanger performance can be improved by using various augmentation techniques. Generally in shell and tube heat exchanger segmental baffles are used. In this study the performance improvement of heat exchanger is done using slotted baffle instead of segmented baffle. Present study aims at developing a heat exchanger model with slotted baffle and comparing it experimentally with the heat exchanger having segmental baffle for performance improvement. For this study some literature review is done as follows.

Sunilkumar Shinde and Mustansir Hatim Pancha (2012). In this study author has given the comparative study of segmental baffle and continuous helical baffle. The comparison is done using Kern method. This paper gives the mathematical formulae for comparison.

Bin Gao, Qincheng Bi, et. al. (2015). In this author has performed the experimental study on shell and tube heat exchanger for checking the performance with discontinuous helical baffle. Study gives us some drawbacks of segmental baffle which are overcome by helical baffle.

Alok Vyas and Prashant Sharma (2013). In this paper author has discussed about the experimental study to improve performance of tubular heat exchanger. In this paper some thermal design factors that are to be taken into account while designing the tubes of the tubular heat exchanger has been discussed.

The main objectives of this study are: Development of experimental set up, Experimentation, Comparison of results of segmental baffle with that of slotted baffles.

\section{Development of Model}

\section{Design data}

Table 1 Properties of fluid

\begin{tabular}{|c|c|c|}
\hline Properties & Hot fluid & Cold fluid \\
\hline Inlet temp & $60^{\circ} \mathrm{C}$ & $30^{\circ} \mathrm{C}$ \\
\hline Outlet temp & $53^{\circ} \mathrm{C}$ & $35^{\circ} \mathrm{C}$ \\
\hline Density $(\rho)$ & $984.1 \mathrm{KG} / \mathrm{M} 3$ & 994.09 \\
\hline $\begin{array}{c}\text { Dynamic } \\
\text { viscosity }(\mu)\end{array}$ & $4.715 \times 10^{-4}$ & $7.22 \times 10^{-4}$ \\
\hline $\begin{array}{c}\text { Thermal } \\
\text { conductivity(k) }\end{array}$ & 0.65167 & 0.62416 \\
\hline Specific heat(cp) & $4.065 \times 10^{3}$ & $4.068 \times 10^{3}$ \\
\hline Prandlt No(PR) & 2.9421 & 4.7085 \\
\hline
\end{tabular}


Tube outside diameter (Do): $19 \mathrm{~mm}$

Tube inside diameter (Di): $18.2 \mathrm{~mm}$

Length of the tubes (L): $1 \mathrm{~m}$

Baffle spacing $\left(\mathrm{L}_{b}\right): 250 \mathrm{~mm}$

Assume mass flow rate $1 \mathrm{Kg} / \mathrm{sec}$

Calculations:

$$
\begin{gathered}
\mathrm{Q}=[\mathrm{mCp}(\Delta \mathrm{t})] \text { cold } \\
=\left[1 * 4.068 \times 10^{3 *}(35-30)\right] \\
\mathrm{Q}=20.34 \mathrm{Kw}
\end{gathered}
$$

Let select $\mathrm{U}=300$

(Kern method)[1][5]

We know that,

$$
\mathrm{Q}=\mathrm{UA} \theta_{\mathrm{m}}
$$

Where $\theta m=\log$ mean temp. Difference $=24$

$$
\therefore \quad \mathrm{Q}=300 * \mathrm{~A}^{*} 24
$$

\section{$\mathrm{A}=2.825 \mathrm{~m}^{2}$}

But

$$
\begin{aligned}
& A=\pi^{*} d_{o}^{*} L^{*} n \\
& n=47.20
\end{aligned}
$$

\section{$\therefore$ No of tubes $=48$}

Tube side Heat transfer coefficient:

$A c=(\pi / 4)^{*} d_{i}^{2 *} n=0.01211 m^{2}$

$\mathrm{Gs}=\dot{\mathrm{m} c} / \mathrm{Ac}=82.5$

$$
\mathrm{hi}=0.023 \times \frac{\mathrm{k}}{\mathrm{di}} \times\left(\frac{\mathrm{Gs} \times \mathrm{di}}{\mu}\right)^{0.8} \times\left(\frac{\mu \times \mathrm{Cp}}{\mathrm{K}}\right)^{0.4}
$$

$$
\mathrm{hi}=806.89 \mathrm{~W} / \mathrm{m}^{2} \mathrm{k}
$$

Shell side Heat transfer coefficient: Let selecting square pitch For square pitch,

$$
d e=\frac{4 \times\left(P t^{2}-\left(\frac{\pi}{4}\right) \times d o^{2}\right)}{\pi \times \text { do }}
$$

Where Pt $=$ Pitch $=1.25^{*} \mathrm{do}=23.81 \mathrm{~mm}$

$$
d e=18.84 \mathrm{~mm}
$$

Let Diameter of shell Ds $=250 \mathrm{~mm}$

Length of baffle span $\mathrm{Lb}=250 \mathrm{~mm}$

$$
\mathrm{As}=\frac{(\mathrm{Pt}-\mathrm{do}) \times \mathrm{Ds} \times \mathrm{Lb}}{P t}
$$

$$
\begin{array}{r}
\frac{h o \times d e}{k}=0.36 \times\left(\frac{d e \times G s}{\mu}\right)^{0.55} \times\left(\frac{C p \times \mu}{\mathrm{K}}\right)^{0.33} \times\left(\frac{\mu}{\mu \mathrm{w}}\right)^{0.14} \\
\frac{1}{U}=\left(\frac{1}{h i} \times \frac{d o}{d i}\right)+\left(\frac{1}{h o}\right)+0.0004+0.0004
\end{array}
$$

$\therefore \quad \mathrm{U}=343.19$

But

$$
\mathrm{Q}=\mathrm{UA} \theta_{\mathrm{m}}
$$

$\therefore \quad$ Required area $=2.4694 \mathrm{~m}^{2}$

This is less than available area so design is safe.

In this experiment instead of segmental baffle slotted baffles are used which is shown in figure below.

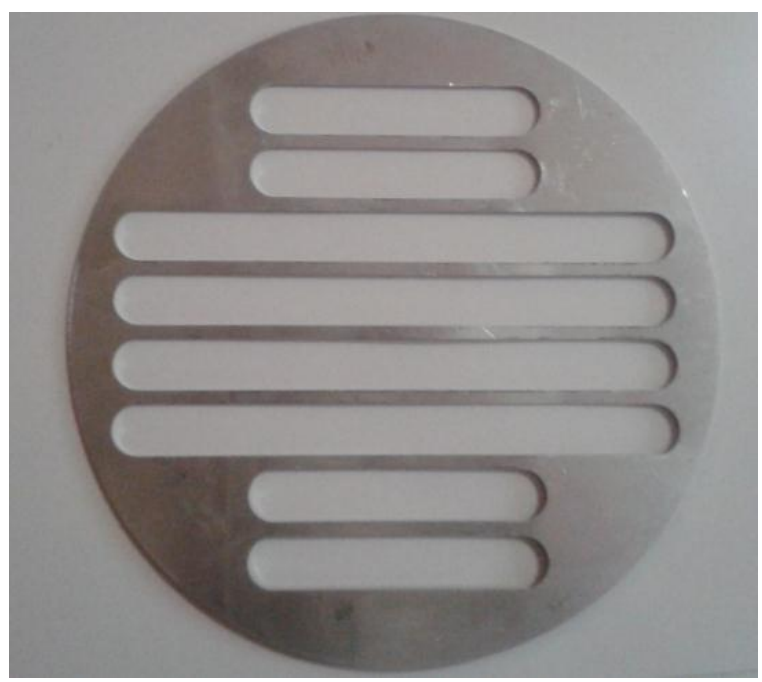

Figure 1 Slotted baffle

These baffles are placed at $90^{\circ}$ to each other while fitting pipes into it so that flow gets turbulence.

\section{Experimental setup}

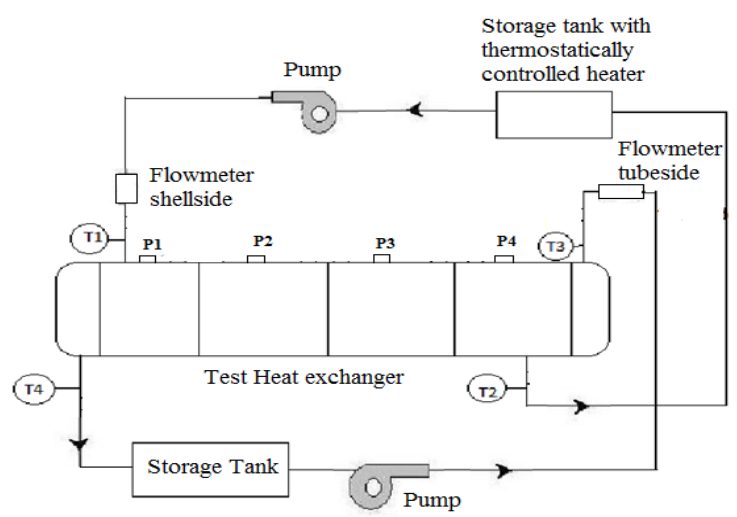

Figure 2 Line diagram of Experimental setup 


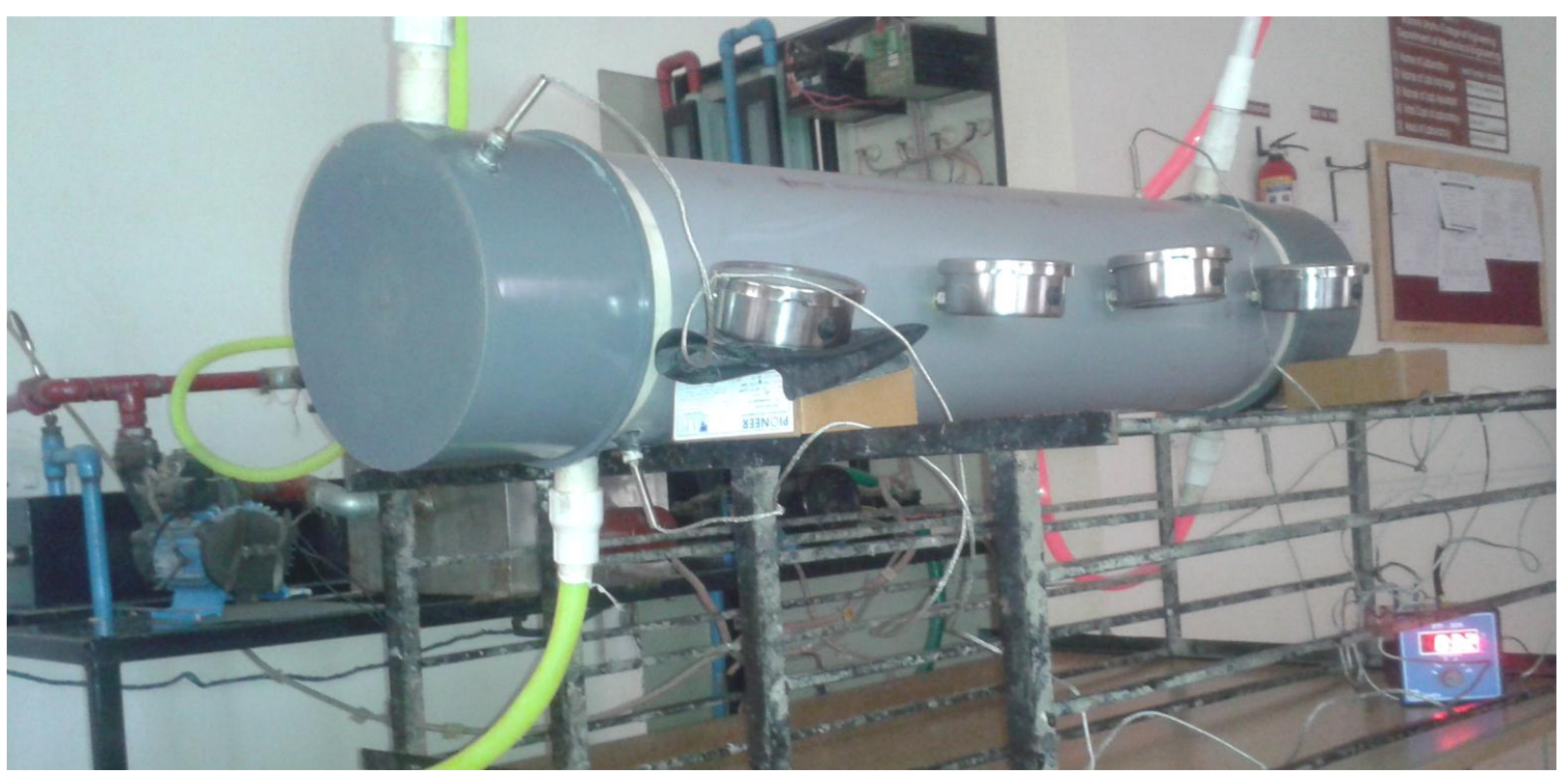

Figure 3 Working Experimental Setup

The experimental setup for testing of heat exchanger is as shown in figure above.

Hot water is flowing on shell side of the HEX from top side of the shell of HEX and leaves the shell from bottom side. Hot water from storage tank is taken through a water pump towards the HEX. Flow of water is controlled by using a flow control valve. Flow rate of the water is measured through a Rotameter. For getting hot water a thermostatically controlled water heater is used. This is a immersion type of heater. It is fixed in the storage tank permanently. Various water temperatures can be achieved and maintained by using this heater.

Cold water is used as working fluid in this heat exchanger. Cooling water at atmospheric temperature is stored in storage tank placed near Heat exchanger. It is pumped to the heat exchanger though pump and enter tube side from top and leaves tube side from bottom side of the heat exchanger. Flow of the water is controlled though a valve. Due to flow of Hot and cold water heat exchange takes place in exchanger.

For measurement of the pressure a pressure gauge is installed at each section of the Heat exchanger on shell side.

For temperature measurement RTD temperature sensors are used. They are connected to the digital temperature indicator which gives direct reading of the temperature.

\section{Experimental Procedure}

- Make all electrical and piping connections of heat exchanger and pump line etc.

- $\quad$ Shell priming is done by filling nearly $2 / 3$ part of the shell of the heat exchanger.

- Set the heater to required temperature

- Start the mains supply of the setup

- Start heater
- $\quad$ Start pumps of shell and tube side

- Wait till the set temperature of heater is achieved.

- After reaching steady state start taking readings

- Take temperature readings by applying knob of the digital temperature indicator

- Take pressure reading directly from pressure gauge.

- Repeat the same procedure for various temperatures.

- $\quad$ After taking all readings switch off all devices and cut off mains power.

- At last drain out the water in shell and tube side

\section{Results and discussion}

After doing the experimental analysis following results were obtained. From observing the result table we can see the improvement in the heat transfer rate of the heat exchanger using slotted baffle instead of segmental baffle. Also the effectiveness of the heat exchanger increases for slotted baffle.

Table 2 Heat transfer rate and Effectiveness of heat exchanger with segmental baffle

\begin{tabular}{|c|c|c|}
\hline Case no. & $\begin{array}{c}\text { Q heat transfer } \\
\text { rate }\end{array}$ & $\begin{array}{c}\text { Effectiveness of } \\
\text { hex }\end{array}$ \\
\hline 1 & 4.16328 & 0.6 \\
\hline 2 & 6.24492 & 0.6 \\
\hline 3 & 6.9388 & 0.588235294 \\
\hline 4 & 7.63268 & 0.55 \\
\hline 5 & 7.63268 & 0.5 \\
\hline 6 & 9.02044 & 0.52 \\
\hline 7 & 9.71432 & 0.482758621 \\
\hline 8 & 10.4082 & 0.46875 \\
\hline 9 & 10.4082 & 0.441176471 \\
\hline 10 & 11.79596 & 0.447368421 \\
\hline 11 & 12.48984 & 0.45 \\
\hline 12 & 13.8776 & 0.465116279 \\
\hline
\end{tabular}


Table 3 Heat transfer rate and Effectiveness of heat exchanger with slotted baffle

\begin{tabular}{|c|c|c|}
\hline Case no. & $\begin{array}{c}\text { Q heat transfer } \\
\text { rate }\end{array}$ & $\begin{array}{c}\text { Effectiveness of } \\
\text { hex }\end{array}$ \\
\hline 1 & 4.16328 & 0.6 \\
\hline 2 & 6.24492 & 0.6 \\
\hline 3 & 6.9388 & 0.588235294 \\
\hline 4 & 8.32656 & 0.6 \\
\hline 5 & 8.32656 & 0.545454545 \\
\hline 6 & 9.71432 & 0.583333333 \\
\hline 7 & 11.79596 & 0.586206897 \\
\hline 8 & 12.48984 & 0.5625 \\
\hline 9 & 12.48984 & 0.529411765 \\
\hline 10 & 14.57148 & 0.552631579 \\
\hline 11 & 15.26536 & 0.536585366 \\
\hline 12 & 16.65312 & 0.558139535 \\
\hline
\end{tabular}

\section{Comparison of the results for segmental baffle and slotted baffle heat exchanger}

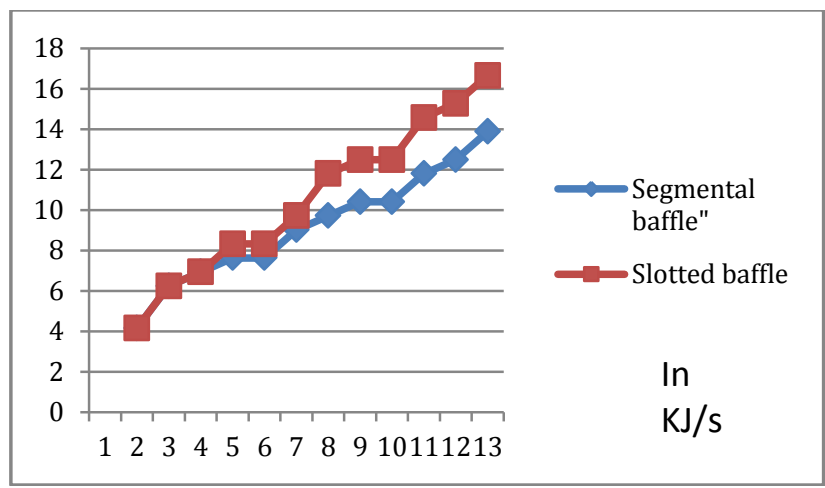

Figure 4 Comparison of heat transfer rate of heat exchanger using segmental baffle and slotted baffle

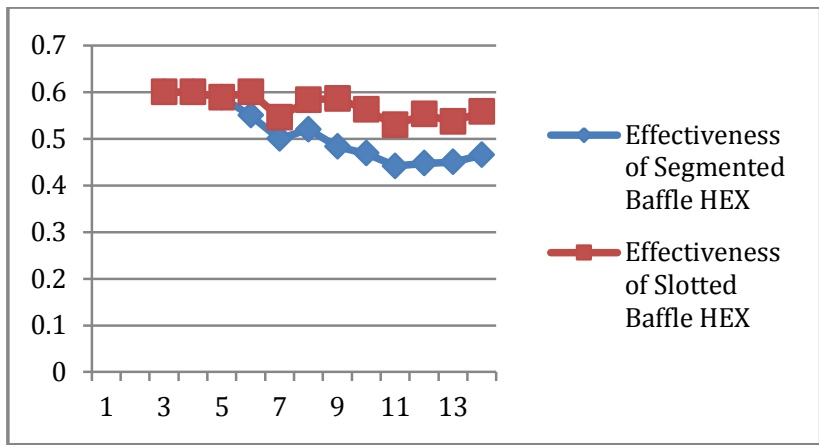

Figure 5 Comparison of effectiveness of heat exchanger using segmental baffle and slotted baffle
Figure 4 shows the variation of heat transfer rate of heat exchanger for segmental baffle and for slotted baffle. This is a plot of Heat transfer rates at various cases. Figure 5 shows the variation of effectiveness of heat exchanger for segmental baffle and for slotted baffle. This is plot of effectiveness of HEX at various cases.

\section{Conclusion}

After analyzing the results of the experimental analysis it is observed that heat transfer rate of the heat exchanger increases for slotted baffle that of segmental baffle. Also the effectiveness of heat exchanger increases for slotted baffle heat exchanger that of segmental baffle heat exchanger.

\section{Nomenclature}

HEX - Heat exchanger $\mathrm{Q}$ - Heat transfer rate $\mathrm{m}_{\mathrm{h}}$ - Mass flow rate of hot fluid

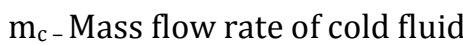
$\mathrm{Cp}_{\mathrm{h}-S p e c i f i c}$ heat of hot water $\mathrm{Cp}_{\mathrm{c}}$ - Specific heat of cold water $\Delta \mathrm{T}_{\mathrm{c}}$ - Temperature Difference for cold water $\Delta \mathrm{T}_{\mathrm{h}}$ - Temperature Difference for hot water $\theta \mathrm{m}=\mathrm{Log}$ mean temp. Difference

\section{References}

Su Thet Mon Than, Khin Aung Lin (2008), Heat Exchanger design, World Academy of Science, Engineering and Technology, pp 604-612.

Bin Gao, Qincheng Bi (2015), Experimental study of effects of baffle helix angle on shell-side performance of shell-andtube heat exchangers with discontinuous helical baffles, ELSEVIER, ,pp 48-57.

Alok Vyas, Mr. Prashant Sharma (2013), An experimental analysis study to improve performance of tubular heat exchangers, IJERA, Vol 3, pp 1804-1809.

Sunilkumar Shinde, Mustansir Hatim Pancha (2012) Comparative thermal performance analysis of segmental baffle heat exchanger with continuous helical baffle heat exchanger using kern method, IJERA, Vol 2, pp2264-2270.

B. Peng., Q. W. Wang (2007), An experimental study of shell and tube heat exchangers with continuous helical baffle ASME, Vol 129, PP 1425-1431. 